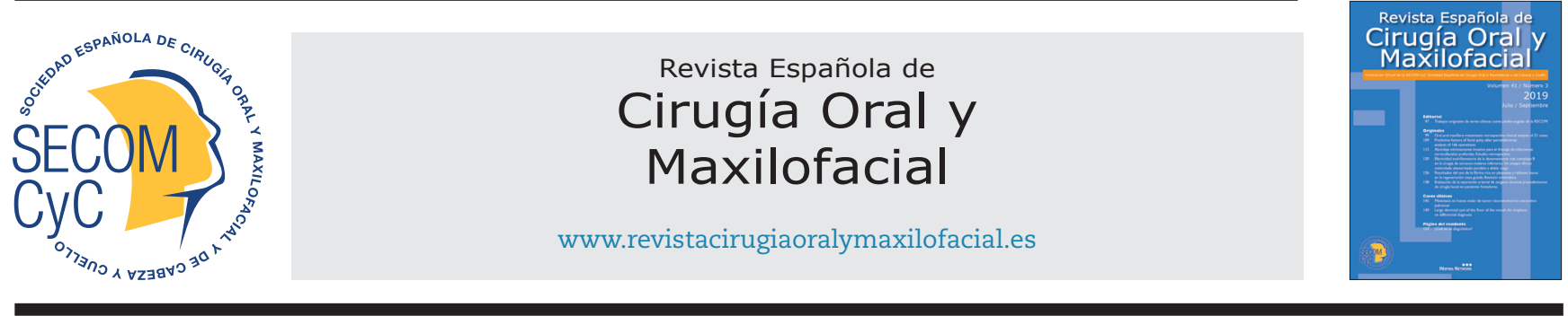

\title{
Original
}

\section{Predictive factors of facial palsy after parotidectomy: analysis of 166 operations}

\author{
Ana Rita Lameiras ${ }^{a, b}$, Hugo Estibeiro ${ }^{a}$, Pedro Montalvão y Miguel Magalhães ${ }^{a}$
}

aOtolaryngology Department, Instituto Português de Oncologia de Lisboa Francisco Gentil, EPE, Lisbon, Portugal. 'Otolaryngology Department, Centro Hospitalar Barreiro Montijo, EPE, Portugal

\section{A R T I C L E I N F O}

\section{Article history:}

Received 17 July 2018

Accepted 21 January 2019

\section{Keywords:}

Parotidectomy, facial nerve, facial palsy, complications.

\begin{abstract}
A B S T R A C T
Objectives: Facial nerve injury is one of the most important complications in parotid gland surgery. This study aims to identify possible predictive factors for iatrogenic facial paralysis in parotidectomy.

Material and method: We performed a retrospective analysis of cases of parotidectomy in the treatment of parotid tumors carried out at a Portuguese Oncology Institute, during a period of 25 years. Socio-demographic data, patient's comorbidities, surgical procedure and tumor histopathology were reviewed.

Results: The study sample consisted of a total of 166 patients ( 86 males and 80 females), with a mean age of $56.9 \pm 16.8$ years. In 62 cases ( $37.4 \%$ ), some degree of postoperative facial palsy was observed. The extent of surgery ( $\mathrm{rho}=0.177 ; p=0.023$ ) and tumor size ( $\mathrm{rho}=0.159$; $p=0.045$ ) showed correlation with facial nerve injury. The factors malignancy of the lesion (rho $=0.568 ; p<0.001$ ), extension of the surgery (rho $=0.485 ; p<0.001$ ) and enlargement of the excision to the skin ( $r h o=0.7211 ; p<0.001)$ correlated with the facial nerve sacrifice. The percentage of persistent facial palsy was only $7.6 \%$.

Conclusions: Tumors of larger size and with extension to the deep lobe of the parotid are significantly correlated with iatrogenic facial palsy. Malignancy of the lesion and greater extension of surgery correlate with facial nerve sacrifice.
\end{abstract}

Part of this paper was presented in the $64^{\text {th }}$ National Congress of the Portuguese Society of Otorhinolaryngology that took place in Viana do Castelo, Portugal, between 5 and 7 of May of 2017

${ }^{*}$ Corresponding author:

E-mail address: rita_lameiras@hotmail.com (Ana Rita Lameiras, MD).

DOI: 10.20986/recom.2019.1043/2019

1130-0558/@ 2019 SECOM. Publicado por Inspira Network. Este es un artículo Open Access bajo la licencia CC BY-NC-ND (http:// creativecommons.org/licenses/by-nc-nd/4.0/). 


\section{Factores predictivos de parálisis facial después de la parotidectomía: análisis de 166 operaciones}

\section{R E S U M E N}

Keywords:

Parotidectomía, nervio facial, parálisis facial, complicaciones.
Objetivos: La lesión del nervio facial es una de las complicaciones más importantes en la cirugía de la glándula parótida. Este estudio tiene como objetivo identificar posibles factores predictivos de parálisis facial yatrogénica en la parotidectomía.

Material y método: Se realizó un análisis retrospectivo de casos de parotidectomía en el tratamiento de tumores parotídeos realizados en un instituto portugués de oncología durante un periodo de 25 años. Se han revisado los datos sociodemográficos, las comorbilidades del paciente, el procedimiento quirúrgico y la histopatología tumoral.

Resultados: La muestra del estudio consistió en un total de 166 pacientes ( 86 hombres y 80 mujeres), con una edad media de 56,9 $\pm 16,8$ años. En 62 casos (37,4 \%) se observó cierto grado de parálisis facial postoperatoria. La extensión de la cirugía ( $r h o=0,177 ; p=0,023$ ) y el tamaño del tumor ( $r h o=0,159 ; p=0,045$ ) mostraron una correlación con la lesión del nervio facial. Los factores malignidad de la lesión ( $r h o=0,568 ; p<0,001$ ), la extensión de la cirugía (rho = 0,485; $p<0,001$ ) y la ampliación de la escisión a la piel (rho $=0,7211 ; p<0,001)$ se correlacionaron con el sacrificio del nervio facial. El porcentaje de parálisis facial persistente fue solo del 7,6 \%. Conclusiones: Los tumores de mayor tamaño y con extensión al lóbulo profundo de la parótida se correlacionan significativamente con la parálisis facial yatrogénica. La malignidad de la lesión y una mayor extensión de la cirugía se correlacionan con el sacrificio del nervio facial.

\section{INTRODUCTION}

Salivary gland tumors represent 3-10\% of all head and neck neoplasms ${ }^{1}$. About $80 \%$ of the salivary gland tumors occur in the parotid gland ${ }^{2}$. Surgical intervention is the mainstay of treatment for parotid gland tumors ${ }^{3}$.

The parotid gland is closely related to the facial nerve. Facial palsy (FP) is one of the most serious complications that can occur in parotid gland surgery and the primary concern of both surgeons and patients. In the literature, the incidence of transient facial weakness after parotid surgery ranges from $10 \%$ to $68 \%$, and long-term dysfunction ranges from $0 \%$ to $19 \% 4$.

It would be advantageous to be able to predict preoperatively the possibility of iatrogenic FP or the need for facial nerve sacrifice in parotidectomy, with the aim of a better surgical planning and informed consent. Several risk factors have been identified for postparotidectomy facial nerve dysfunction, including older age, diabetes, malignancy, larger tumor size, tumors involving the deep lobe of the parotid gland and revision surgery ${ }^{5-7}$. However, the described risk factors vary considerably from study to study. In addition, medical comorbidities, such as diabetes and hypertension, were not included in some of those studies, which complicated the retrospective analysis of risk factors for postparotidectomy FP.

The purpose of this study was to determine possible predictive factors related to the occurrence of FP after parotidectomy in the surgical treatment of parotid gland tumors.

\section{MATERIAL AND METHODS}

This article is a descriptive and longitudinal study. This study is in accordance with the ethics standards of the insti- tute where it was carried out and with the Helsinki declaration.

\section{Patients}

The authors performed a retrospective analysis of cases of parotidectomy in the treatment of parotid tumors carried out at a Portuguese Oncology Institute. Data was obtained from 1991 to 2015. This time frame was selected to provide adequate follow-up of at least 1 year. Patients with pre-operative FP by previously surgery or malignant tumor infiltration were excluded from the study.

\section{Surgical team}

Eight different senior surgeons were involved in the surgeries. The surgical team was characterized by an elevated homogeneity in technical abilities. In result, the factor surgeon experience was not included in the statistical analysis.

\section{Surgical procedure}

After identifying the main trunk of the facial nerve, the overlying parotid tissue is meticulously elevated from the facial nerve. Sequential branching of the nerve is sequentially dissected, until the entire superficial lobe of the parotid gland lying lateral to the facial nerve is delivered. This completes a superficial or lateral parotidectomy. If a total parotidectomy is indicated, the procedure is extended by meticulous dissection of the main trunk and the branches of the facial nerve from the underlying parotid tissue in a gentle and atraumatic fashion. 
This allows the salivary tissue lying deep to the facial nerve to be delivered while preserving the nerve and its function.

Superficial parotidectomy was the approach used in cases of fine-needle aspiration cytology suggestive of benignity with tumor limited to the superficial lobe of the parotid gland. We do not support minimal parotid surgery as tumor enucleation.

Total parotidectomy was performed in cases of fine-needle aspiration cytology suggestive of malignancy, in benign tumor originating within or with extension to the deep lobe and in parotidectomy totalization by tumor recurrence in the remaining gland tissue.

Facial nerve function was monitored via visual control by an assistant surgeon. Electromyographic nerve monitoring was not routinely used.

\section{Facial nerve weakness}

Clinical evaluation of both preoperative and postoperative facial nerve function was performed via visual control. Postoperative FP was defined as any objective facial weakness in a given area (frontal, zygomatic, buccal, marginal, cervical). A persistent FP was defined by any degree of facial weakness persisting longer than 6 months postoperatively. Postoperative electromyography and electroneurography were not routinely performed.

\section{Variables analysed}

The cases were analysed for socio-demographic data (age, sex), patient's comorbidities (hypertension, vascular arterial disease, diabetes, dyslipidemia, obesity), surgical procedure (laterality, superficial/total parotidectomy, primary/revision surgery, concomitant cervical lymph node dissection, enlargement of the excision to the skin), histopathology (benign/ malignant, tumor dimension) and clinical outcome (involuntary FP/facial nerve sacrifice, involved territory of the face, face motility recovery). The dimensions evaluated (tumor's length and depth) were obtained from histopathological reports and not from clinical staging to give a more precise value.

\section{Statistical analysis}

The authors performed a descriptive analysis of the results, using the mean and SD for continuous variables and frequency for categorical variables. The statistical analysis was performed using Stata 14.0. Spearman's correlation coefficient (rho) was used to evaluate possible factors related to iatrogenic FP. The significance level was set at $p<0.05$.

\section{RESULTS}

The study sample consisted of a total of 166 patients. There were 80 female (48.2\%) and 86 male $(51.8 \%)$ patients, with a mean age of 56.9 years (range 11 to 95 years, SD 16.8).

The frequency of the different comorbidities assessed in the sample was as follows: hypertension $31.9 \%(n=53)$; vas- cular arterial disease $15.7 \%(n=26)$; diabetes $12.1 \%(n=20)$; dyslipidemia $7.2 \%(n=12)$; obesity $7.2 \%(n=12)$.

The surgical procedure was performed on the right parotid gland in 82 (49.4\%) and on the left in 84 (50.6\%) cases. Superficial parotidectomy was performed in 114 (68.7\%) and total parotidectomy in 52 (31.3\%) of the cases. In 18 cases (10. 8\%), the surgery was a revision procedure. Concomitant cervical lymph node dissection was performed in $15.1 \%(n=25)$. The excision was extended to the skin in $7.2 \%(n=12)$.

Histopathology revealed a benign in 124 (74.7\%) and malignant tumor in 42 (25.3\%) cases. Pleomorphic adenoma, followed by Warthin's tumor, was the most frequent diagnose (Table I). The mean tumor size (largest axis) was $2.8 \mathrm{~cm}$ (range: 0.2 to $10 \mathrm{~cm}, \mathrm{SD} 1.7)$. The mean tumor thickness was $1.8 \mathrm{~cm}$ (range: 0.5 to $5.7 \mathrm{~cm}, \mathrm{SD} 1.1$ ).

In 62 cases (37.4\%), some degree of FP was observed postoperatively. Of these, $12.9 \%(n=8)$ resulted from facial nerve sacrifice by malignant tumor infiltration (therapeutic indication) (Figure 1).

In the remaining $87.1 \%(n=54)$, the injury of the facial nerve was involuntary and not detected during the procedure (FP not predicted intra-operatively). In these cases, the territory of the marginal branch was the most frequently involved (67.2\%).

In cases of facial nerve sacrifice by malignant tumor infiltration, it was performed when feasible intra-operatively repair with nerve cable grafting. The donor nerve used was usually the greater auricular nerve or, in alternative, the sural nerve.

In the group of involuntary (not detected) injury of the facial nerve with post-operatively FP, the patients started high

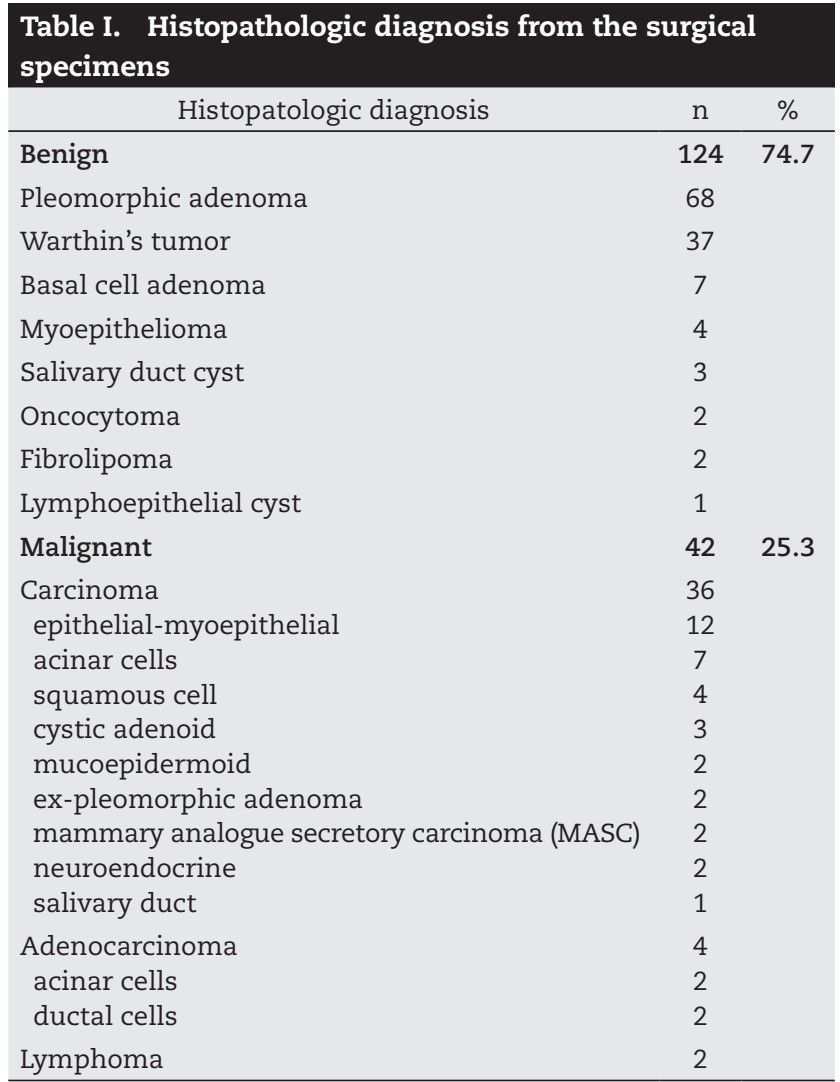




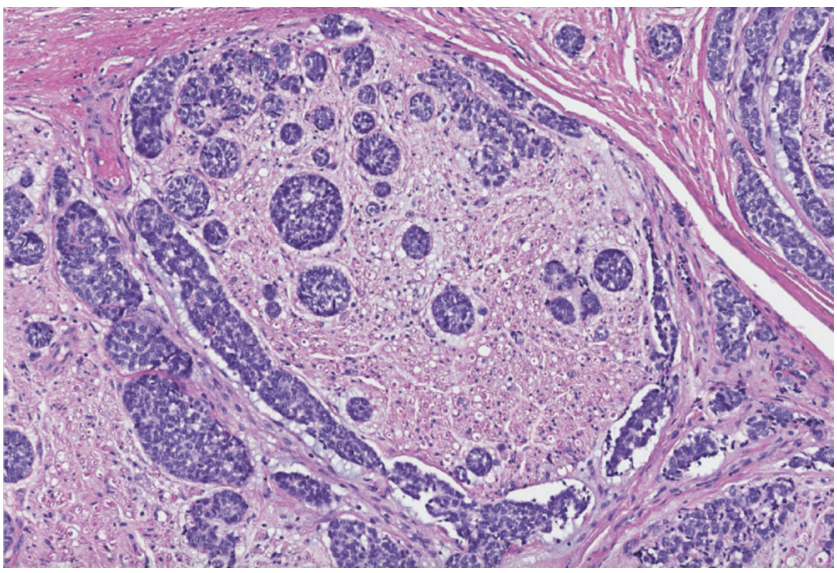

Figure 1. Micrograph showing a segment of facial nerve with perineural invasion of mucoepidermoid carcinoma. H\&E stain.

dose steroids and tailored facial exercises. Complete recovery was observed in $77.8 \%(n=42 / 54)$ of the patients. In only $5.6 \%(n=3 / 54)$ there was any recovery. Considering the total study sample, excluding the cases of facial nerve sacrifice, temporary facial nerve dysfunction was observed in $26.6 \%$ ( $n=42 / 158$ ), whereas persistent FP occurred in $7.6 \%$ of the cases $(n=12 / 158)$.

The extension of surgery (rho $=0.177 ; p=0.023$ ) and tumor size (rho $=0.159 ; p=0.045$ ) showed correlation with iatrogenic facial nerve injury. The other factors analysed were not found to be statistically significant risk factors (Table II).

The factors malignancy of the lesion (rho $=0.568 ; p<0.001$ ), extension of the surgery ( $r h o=0.485 ; p<0.001$ ) and enlargement of the excision to the skin (rho $=0.7211 ; p<0.001$ ) correlated with the facial nerve sacrifice (Table III).

\section{DISCUSSION}

An accurate informed consent is an important part of the preoperative process in any surgery. FP is one of the most serious complications that can occur in parotid gland surgery. It would be advantageous to be able to predict preoperatively the possibility of iatrogenic FP or the need for facial nerve sacrifice in parotidectomy, with the aim of a better surgical planning and informed consent.

The exact mechanism of postparotidectomy FP in the presence of anatomically intact facial nerve is still poorly understood. Neural elongation was proposed as the most probable factor involved in facial nerve dysfunction after surgery of the parotid gland. Peripheral nerves have been found to follow a peculiar stress-strain curve with zones of straightening and elastic elongation, followed by mechanical rupture. Nerve elongation of $6 \%$ seems to cause perineurium tears with disturbance of the intrafascicular homeostasis and unrecoverable loss of the compound action potencial (neurotmesis). After this type of lesion the nerve remains grossly normal, although not functional, which may justify the absence of injury perception by the surgeon. On the other hand, in less significant neural
Table II. Univariate analysis of risk factors for iatrogenic facial palsy (total sample)

\begin{tabular}{lcc} 
& $\begin{array}{c}\text { Rho } \\
\text { (Spearman) }\end{array}$ & p-value \\
\hline Age (years) & -0.009 & 0.907 \\
Gender (ref: female) & -0.053 & 0.499 \\
Comorbidities (ref: no) & & \\
$\quad$ Hypertension & -0.021 & 0.786 \\
Vascular arterial disease & -0.024 & 0.755 \\
Diabetes & -0.095 & 0.226 \\
$\begin{array}{l}\text { Dyslipidemia } \\
\text { Obesity }\end{array}$ & -0.071 & 0.362 \\
Laterality (ref: left) & -0.023 & 0.767 \\
$\begin{array}{l}\text { Surgery extension } \\
\text { (ref: superficial parotidectomy) }\end{array}$ & 0.038 & 0.630 \\
Surgery type (ref: primary surgery) & 0.177 & 0.023 \\
$\begin{array}{l}\text { Concomitant cervical lymph node } \\
\text { dissection (ref: no) }\end{array}$ & 0.011 & 0.887 \\
$\begin{array}{l}\text { Enlargement of the excision to the skin } \\
\text { (ref: no) }\end{array}$ & 0.128 & 0.102 \\
Histopatologic diagnosis (ref: benign) & 0.121 & 0.120 \\
$\begin{array}{l}\text { Tumor dimension } \\
\text { Tumor's length }\end{array}$ & 0.009 & 0.905 \\
Tumor's depth & 0.159 & 0.045 \\
\hline
\end{tabular}

Table III. Univariate analysis of risk factors for need of facial nerve sacrifice

\begin{tabular}{lcc} 
& $\begin{array}{c}\text { Rho } \\
\text { (Spearman) }\end{array}$ & $p$-value \\
\hline Age (years) & -0.084 & 0.302 \\
Gender (ref: female) & 0.059 & 0.648 \\
Comorbidities (ref: no) & & \\
Hypertension & 0.223 & 0.082 \\
Vascular arterial disease & 0.090 & 0.486 \\
Diabetes & 0.046 & 0.722 \\
Dyslipidemia & 0.121 & 0.351 \\
Obesity & -0.108 & 0.403 \\
Laterality (ref: left) & 0.046 & 0.724 \\
Surgery extension (ref: superficial & 0.485 & $<0.001$ \\
parotidectomy) & -0.002 & 0.986 \\
Surgery type (ref: primary surgery) & & \\
Concomitant cervical lymph node & 0.238 & 0.063 \\
dissection (ref: no) & & \\
Enlargement of the excision to the skin & 0.721 & $<0.001$ \\
(ref: no) & & \\
Histopatologic diagnosis (ref: benign) & 0.568 & $<0.001$ \\
Tumor dimension & & \\
$\quad$ Tumor's length & 0.216 & 0.097 \\
Tumor's depth & 0.235 & 0.230 \\
\hline
\end{tabular}

elongation there is no disruption of the endoneurium (neuropraxia or axonotmesis), occurring complete recovery of the nerve function after time ${ }^{8}$. In our series, there was complete recovery of the face motility in $77.8 \%$ of the patients with postoperative FP not resulting from facial nerve sacrifice. So, our results suggest that most cases of FP postparotidectomy are transient and reversible as result of neuropraxia or axonotmesis by neural stretching during the dissection. 
In this series, similarly to other studies, the marginal branch was the most frequently involved after parotidectomy. This facial nerve branch seems to be more prone to injury during parotidectomy. Possible reasons that make the marginal branch more liable to be injured and stretched during surgery include the relatively fewer connecting anastomoses and its thinner diameter and longer tracts embedded in the parotid gland. Furthermore, some parotid tumors, such as Warthin tumor, have a tendency to be located in the lower pole of the parotid gland and, therefore, in the path of this facial nerve branch?.

Previous reports identified different risk factors for postparotidectomy $\mathrm{FP}^{5-7}$. In our series, contrary of what we might expect, only the extension of surgery and tumor size showed correlation with iatrogenic facial nerve injury. A total parotidectomy, with excision of the deep lobe of the parotid gland, requires a more extensive dissection of the facial nerve with an increased risk of neural elongation and mechanical rupture. We performed total parotidectomy in all malignant tumors, even if low-graded, in order to address the possible intraglandular spread of lymph node metastases, due to the anatomical and oncological importance of the deep parotid lymph nodes ${ }^{10,11}$. On the other hand, larger tumor size showed to be associated with a more intimate relationship between the facial nerve and the tumor, with increased risk of nerve stretching, and possible tumor extension to the deep lobe of the parotid gland. These risk factors should be taken in account in the preoperative evaluation and demand a much more careful technique during nerve dissection.

Although not identified in our series, the literature points out as risk factors for postparotidectomy FP older age ${ }^{4}$, diabetes $^{7}$ and revision surgery ${ }^{6}$. Neural regeneration seems to be poorer in aged patients. Animal experiments have shown that axonal regrowth of the facial nerve is delayed and the reinnervation pattern is pathological altered in aged individuals ${ }^{12}$. Motor nerve conduction velocity and amplitude are lower in diabetic patients compared with nondiabetic patients. Also, in diabetic patients, the Schwann cells and myelin sheaths of nerves are much more prone to damage than in nondiabetic patients ${ }^{13}$. The correlation observed in some studies between revision surgery and long-term facial deficits might be explain by the greater risk of nerve stretching in revision parotidectomy cases when freeing the fine nerve branches from the surrounding scar tissue. Additionally, it is often difficult to differentiate scar tissue from small nerve fibers ${ }^{6}$.

Sacrifice of the facial nerve is indicated in the presence of preoperative FP and tumor encasement or infiltration. Facial nerve dissection should always be macroscopically radical, avoiding macroscopic residual tumor. To best to our knowledge, we have found no previous studies addressing the predictive factors of facial nerve sacrifice. The factors malignancy of the lesion, extension of the surgery and enlargement of the excision to the skin correlated with the facial nerve sacrifice. Malignancy of the lesion requires a more aggressive surgical approach. In addition, malignant lesions may be associated with tumor's adherence and facial nerve infiltration. Enlargement of the excision to the skin, as far as we know, was not evaluated in previous studies. This procedure is required to perform a complete tumoral excision in the presence of a malignant tumor with skin extension, and reflects a more extensive and aggressive tumor. These factors should be considered preoperatively for a more accurate informed consent about the possibility of facial nerve sacrifice in patients without preoperative FP.

In the present study, electromyography (EMG) was not routinely used. Considering the total study sample and excluding the cases of facial nerve sacrifice, persistent FP was present in $7.6 \%$, which is within the range of long-term FP described in the literature using $\mathrm{EMG}^{14}$. In fact, the value of intraoperative EMG during parotidectomy is controversial. Previous literature data suggest the benefit of neuromonitoring in minimizing risk of iatrogenic nerve injury. In contrast, authors refer poor sensitivity of intraoperative electromyographic facial nerve monitoring, with facial nerve injury being correctly predicted only in one fourth of the cases and EMG remaining silent during the surgery in $75 \%$ of patients with postoperative $\mathrm{FP}^{15}$. Others studies, concluded that EMG in primary parotid surgery, in addition to visual facial observation, not diminish the incidence of postoperative FP, not advocating the standardized use of facial nerve monitoring in parotid surgery ${ }^{16}$. Application of standardized operation procedure and a high level of the operative surgeons' experience may explain the absence of increased risk of FP without intraoperative EMG.

The exact significance of risk factors of FP postparotidectomy remains controversial, because the inconsistency of findings between the different studies. Data should be confirmed by prospective studies with larger number of patients that would provide the statistical power to detect associations that may be difficult to detect in smaller cohorts or by meta-analysis.

As limitations of the present study we point out its retrospective nature and be based on the experience of only one tertiary center. Despite these limitations, this is the first study that evaluates the variables concomitant cervical lymph node dissection and enlargement of the excision to the skin for postparotidectomy FP, and studies the predictive factors of facial nerve sacrifice. In addition, cases were reviewed for patient's comorbidities, which could complicate the analysis of the predictive factors of FP after parotid gland surgery.

\section{CONCLUSION}

FP is one of the most serious complications that can occur in parotid gland surgery. Recognize preoperatively the risk factors for iatrogenic FP or need for facial nerve sacrifice in parotidectomy is advantageous for a better surgical planning and informed consent.

A total parotidectomy requires a more extensive dissection of the facial nerve with an increased risk of neural lesion. Large tumors may present a more intimate relationship with the facial nerve and extension to the deep lobe of the parotid gland. Malignant tumors require a more aggressive surgical approach and may be associated with need of facial nerve sacrifice for therapeutic purpose.

The factors age, sex, patient's comorbidities (hypertension, vascular arterial disease, diabetes, dyslipidemia, obesity), lesion laterality, revision surgery and concomitant cervical lymph node dissection were not found to be statistically significant risk factors for iatrogenic FP or need for facial nerve sacrifice in parotidectomy. 
In conclusion, patients should be informed before parotidectomy that tumors of larger size and excision of the deep lobe of the parotid gland are risk factors for transient and longterm facial deficits. They should also be informed that malignancy of the lesion and greater extension of surgery correlate with facial nerve sacrifice.

\section{CONFLICTS OF INTEREST}

None. This research did not receive any specific grant from funding agencies in the public, commercial, or not-for-profit sectors

\section{R E F E R E N C E S}

1. Foresta E, Torroni A, Di Nardo F, de Waure C, Poscia A, Gasparini $G$, et al. Pleomorphic adenoma and benign parotid tumors: extracapsular dissection vs superficial parotidectomy - review of the literature and meta-analysis. Oral Surg Oral Med Oral Pathol Oral Radiol. 2014;117(6):663-76. DOI: 10.1016/j. oooo.2014.02.026.

2. Stryjewska-Makuch G, Kolebacz B, Janik MA, Wolnik A. Increase in the incidence of the parotid gland tumors in the years 2005-2014. Otolaryngol Pol. 2017;71(2):29-34. DOI: 10.5604/01.3001.0009.8412.

3. Zheng CY, Cao R, Gao MH, Huang ZQ, Sheng MC, Hu YJ. Comparison of surgical techniques for benign parotid tumours: a multicentre retrospective study. Int J Oral Maxillofac Surg. 2018 Aug 20. pii: S0901-5027(18)30317-5. DOI: $10.1016 / j$. ijom.2018.07.023. [Epub ahead of print].

4. Ruohoalho J, Mäkitie AA, Aro K, Atula T, Haapaniemi A, KeskiSäntti H, et al. Complications after surgery for benign parotid gland neoplasms: A prospective cohort study. Head Neck. 2017;39(1):170-7. DOI: 10.1002/hed.24496.

5. Preis M, Soudry E, Bachar G, Shufel H, Feinmesser R, Shpitzer T. Predicting facial nerve invasion by parotid gland carcinoma and outcome of facial reanimation. Eur Arch Otorhinolaryngol. 2010;267(1):107-11. DOI: 10.1007/s00405-009-0968-x.
6. Bittar RF, Ferraro HP, Ribas MH, Lehn CN. Facial paralysis after superficial parotidectomy: analysis of possible predictors of this complication. Braz J Otorhinolaryngol. 2016;82(4):447-51. DOI: 10.1016/j.bjorl.2015.08.024.

7. Yuan X, Gao Z, Jiang H, Yang H, Lv W, Wang Z, et al. Predictors of facial palsy after surgery for benign parotid disease: multivariate analysis of 626 operations. Head Neck. 2009;31(12):158892. DOI: $10.1002 /$ hed.21134.

8. Grewal R, Xu J, Sotereanos DG, Woo SL. Biomechanical properties of peripheral nerves. Hand Clin. 1996;12(2):195-204.

9. Yang HM, Kim HJ, Park HW, Sohn HJ, Ok HT, Moon JH, et al. Revisiting the Topographic Anatomy of the Marginal Mandibular Branch of Facial Nerve Relating to the Surgical Approach. Aesthet Surg J. 2016;36(9):977-82. DOI: 10.1093/asj/sjw045.

10. Klussmann JP, Ponert T, Mueller RP, Dienes HP, Guntinas-Lichius O. Patterns of lymph node spread and its influence on outcome in resectable parotid cancer. Eur J Surg Oncol. 2008;34(8):932-7. DOI: 10.1016/j.ejso.2008.02.004.

11. Olsen KD, Quer M, de Bree R, Vander Poorten V, Rinaldo A, Ferlito A. Deep lobe parotidectomy - why, when, and how? Eur Arch Otorhinolaryngol. 2017;274(12):4073-8. DOI: 10.1007/ s00405-017-4767-5.

12. Streppel M, Angelov DN, Guntinas-Lichius O, Hilgers RD, Rosenblatt JD, et al. Slow axonal regrowth but extreme hyperinnervation of target muscle after suture of the facial nerve in aged rats. Neurobiol Aging. 1998;19(1):83-8.

13. Vinik AI, Nevoret ML, Casellini C, Parson H. Diabetic neuropathy. Endocrinol Metab Clin North Am. 2013;42(4):747-87. DOI: 10.1016/j.ecl.2013.06.001.

14. Sood AJ, Houlton JJ, Nguyen SA, Gillespie MB. Facial nerve monitoring during parotidectomy: a systematic review and meta-analysis. Otolaryngol Head Neck Surg. 2015;152(4):631-7. DOI: $10.1177 / 0194599814568779$.

15. Meier JD, Wenig BL, Manders EC, Nenonene EK. Continuous intraoperative facial nerve monitoring in predicting postoperative injury during parotidectomy. Laryngoscope. 2006;116(9):1569-72. DOI: 10.1097/01.mlg.0000231266.84401.55.

16. Grosheva M, Klussmann JP, Grimminger C, Wittekindt C, Beutner D, Pantel M, et al. Electromyographic facial nerve monitoring during parotidectomy for benign lesions does not improve the outcome of postoperative facial nerve function: a prospective two-center trial. Laryngoscope. 2009;119(12):2299305. DOI: 10.1002/lary.20637. 